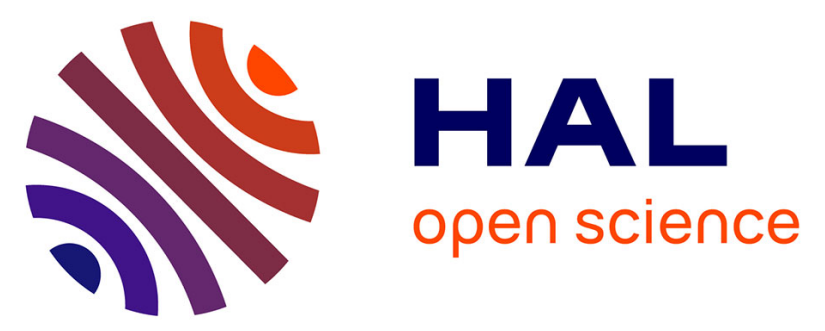

\title{
Coronary angioplasty is associated with a better neurological outcome in the era of modern management of out-of-hospital cardiac arrest.
}

Christine Vaillant, Guillaume Leurent, Ronan Garlantezec, Christophe Thebault, Raphael Martins, Emilie Bot, Isabelle Coudert, Dominique Boulmier, Hervé Le Breton, Marc Bedossa

\section{To cite this version:}

Christine Vaillant, Guillaume Leurent, Ronan Garlantezec, Christophe Thebault, Raphael Martins, et al.. Coronary angioplasty is associated with a better neurological outcome in the era of modern management of out-of-hospital cardiac arrest.: Angioplasty and neurologic outcome of cardiac arrest. International Journal of Cardiology, 2013, 169 (5), pp.e91-2. 10.1016/j.ijcard.2013.10.037 . inserm00906735

\section{HAL Id: inserm-00906735 https://www.hal.inserm.fr/inserm-00906735}

Submitted on 20 Nov 2013

HAL is a multi-disciplinary open access archive for the deposit and dissemination of scientific research documents, whether they are published or not. The documents may come from teaching and research institutions in France or abroad, or from public or private research centers.
L'archive ouverte pluridisciplinaire HAL, est destinée au dépôt et à la diffusion de documents scientifiques de niveau recherche, publiés ou non, émanant des établissements d'enseignement et de recherche français ou étrangers, des laboratoires publics ou privés. 
Title: Coronary angioplasty is associated with a better neurological outcome in the era of modern management of out-of-hospital cardiac arrest.

Short title: Angioplasty and neurologic outcome of cardiac arrest.

Authors: C Vaillant ${ }^{1,2}$, G Leurent ${ }^{* 1,2}, \mathrm{R}$ Garlantezec ${ }^{3}, \mathrm{C}$ Thebault $^{1,2}, \mathrm{R}_{\text {Martins }}{ }^{1,2}, \mathrm{E} \mathrm{Bot}^{4}$, I Coudert ${ }^{4}$,

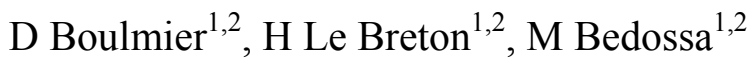

Drs Vaillant and Leurent contributed equally to this article

1-CHU Rennes, Service de cardiologie et maladies vasculaires, Rennes, F-35000, France

2- INSERM, U1099, Rennes, F-35000, France

3- Ecole des Hautes Etudes en Santé Publique, Rennes, F-35000, France

4-CHU Rennes, SAMU, Rennes, F-35000, France

* Corresponding author:

Dr Guillaume LEURENT, Service de cardiologie et maladies vasculaires, CHU de Rennes 2 rue Henri le Guilloux, Rennes, F-35000, France

Tel : +33299282505 Fax: +33299282503ｇuillaume.leurent@,chu-rennes.fr

This paper is not under consideration elsewhere. None of the paper's contents have previously been published. All the authors have read and approved the manuscript.

The authors of this manuscript have certified that they comply with the Principles of Ethical Publishing in the International Journal of Cardiology.

Potential conflict of interest: none.

Key words: cardiac arrest; mild therapeutic hypothermia; prognostic factors; coronary angioplasty; neurologic outcome 
Dear editor,

The prognosis of out-of-hospital cardiac arrest (OHCA) is still poor. Because of its neuro-protective benefits, mild therapeutic hypothermia (MTH) is recommended for comatose adult patients with return of spontaneous circulation (ROSC) after OHCA [1,2]. However, in the era of modern management of OHCA, including MTH, prognostic factors of neurologic outcome for those patients are still unclear.

METHODS: We performed a single-center retrospective review of all the patients admitted to our Intensive Cardiac Care Unit (ICCU) for a non-traumatic OHCA after successful resuscitation, from January 2008 to December 2011. Patients were excluded when OHCA was due to obvious non-cardiac cause and when MTH was not induced, regardless of the reason, such as response to verbal commands after ROSC. Coronary angiography was performed on all patients, except in the case of obvious noncoronary cause (e.g.: known non-ischemic cardiopathy). MTH was initiated as soon as possible, without deferring any required treatments.

The primary outcome was a favorable neurological outcome in living patients at hospital discharge, defined as a Pittsburgh cerebral performance category score (CPC) of 1 or 2 (respectively good recovery or moderate disability). Poor outcomes were category 3, 4 and 5 (respectively severe disability, vegetative state or death) $[3,4]$.

Univariate analysis was performed using the Pearson-Khi square test to identify the risk elements associated with survival. Prognostic factors that were found to be associated with a $p$ value $\leq 0.20$ in the univariate analysis were eligible to be tested in the multivariate model. Multiple imputation was performed to take missing data into account [5]. Logistic regression was performed using a stepwise procedure. The final model included only covariates associated with a $p$ value $\leq 0.05$. Odds ratios (OR) and their confidence interval $(95 \% \mathrm{CI})$ were presented. All calculations were performed using SAS 9.1 (SAS Institute, Cary, NC) and R (http://R-project.org) software. 
RESULTS: Seventy patients who had been admitted for a resuscitated OHCA and treated by MTH in our ICCU constituted our study group (Table 1). The mean age was $59 \pm 7$ years and the men-towomen ratio was 7:1. The OHCA was witnessed in 62 patients $(88 \%)$, with a bystander cardiopulmonary resuscitation (CPR) in $35(50 \%)$. "No-flow" mean-delay was $4.2 \pm 5$ minutes (median: 2) and "low-flow" was $22.6 \pm 16$ (median: 15). The initial rhythm was shockable in 56 patients (80\%). The number of electric shocks was $3.5 \pm 3$ and $3.5 \pm 5 \mathrm{mg}$ epinephrine was administered. The electrocardiogram (ECG) performed at the waning of the resuscitation was normal in 17 patients (24\%). Biomarkers on admission were: arterial $\mathrm{pH}: 7.28 \pm 0.1$, lactate: $3.7 \pm 2 \mathrm{mmol} / \mathrm{L}$, creatinine: $112 \pm 41 \mu \mathrm{mol} / \mathrm{L}$. 
Table 1: Baseline characteristics of patients, according to the outcome.

\begin{tabular}{|c|c|c|c|}
\hline & $\begin{array}{c}\text { Good outcome } \\
n=35\end{array}$ & $\begin{array}{c}\text { Poor outcome } \\
n=35\end{array}$ & p value \\
\hline \multicolumn{4}{|c|}{ Characteristics and medical history } \\
\hline $\begin{array}{l}\text { Male gender } \\
\text { Age } \\
\text { Diabete mellitus } \\
\text { Current smoker } \\
\text { Hyperlipidemia } \\
\text { Hypertension } \\
\text { Known cardiopathy }\end{array}$ & $\begin{array}{c}31(89) \\
55.6 \pm 12 \\
3(8) \\
13(37) \\
17(49) \\
8(23) \\
17(49)\end{array}$ & $\begin{array}{l}29(82) \\
63.1 \pm 15 \\
6(17) \\
12(34) \\
19(54) \\
19(54) \\
24(69)\end{array}$ & $\begin{array}{c}0.73 \\
\mathbf{0 . 0 1 8} \\
0.47 \\
0.80 \\
0.63 \\
\mathbf{0 . 0 1 3} \\
0.08\end{array}$ \\
\hline \multicolumn{4}{|c|}{ Cardiac arrest history } \\
\hline $\begin{array}{c}\text { Chest pain as } 1^{\text {st }} \text { symptom } \\
\text { Location : public place } \\
\text { Time of occurrence (8am-8pm) } \\
\text { Witnessed arrest } \\
\text { Bystander CPR } \\
\text { No-flow mean delay (min) } \\
\text { Low-flow mean delay (min) } \\
\text { Time between collapse and ROSC } \\
\text { VF/VT as initial rhythm }\end{array}$ & $\begin{array}{l}15(43) \\
15(43) \\
28(80) \\
35(100) \\
21(60) \\
2.5 \pm 3 \\
17 \pm 13 \\
20 \pm 16 \\
29(83)\end{array}$ & $\begin{array}{l}12(34) \\
14(40) \\
21(60) \\
27(77) \\
14(40) \\
6 \pm 8 \\
30 \pm 18 \\
37 \pm 16 \\
27(77)\end{array}$ & $\begin{array}{c}0.62 \\
0.23 \\
0.12 \\
\mathbf{0 . 0 0 3} \\
0.47 \\
\mathbf{0 . 0 1 7} \\
\mathbf{0 . 0 0 7} \\
\mathbf{0 . 0 0 5} \\
0.55\end{array}$ \\
\hline \multicolumn{4}{|c|}{ Initial treatment } \\
\hline $\begin{array}{l}\text { Number of electric shocks } \\
\text { Dose of epinephrine (mg) } \\
\text { Antiarrhythmic drugs } \\
\text { Attempted PCI } \\
\text { Successful PCI }\end{array}$ & $\begin{array}{l}3.4 \pm 1 \\
2.6 \pm 2 \\
15(43) \\
21(60) \\
20(57)\end{array}$ & $\begin{array}{l}4.4 \pm 3 \\
4.9 \pm 7 \\
9(25) \\
7(20) \\
5(14)\end{array}$ & $\begin{array}{c}0.68 \\
\mathbf{0 . 0 1 2} \\
0.62 \\
\mathbf{0 . 0 0 2} \\
\mathbf{0 . 0 0 6}\end{array}$ \\
\hline \multicolumn{4}{|c|}{ ECG Patterns } \\
\hline $\begin{array}{c}\text { ST-segment elevation } \\
\text { Unspecific ST or T patterns } \\
\text { Unknown Left Bundle Branch Block } \\
\text { Normal ECG }\end{array}$ & $\begin{array}{l}14(40) \\
9(26) \\
4(11) \\
8(22)\end{array}$ & $\begin{array}{l}12(34) \\
11(31) \\
3(9) \\
9(25)\end{array}$ & $\begin{array}{l}0.8 \\
0.8 \\
0.7 \\
0.7\end{array}$ \\
\hline \multicolumn{4}{|c|}{ Blood biomarkers on admission } \\
\hline $\begin{array}{c}\text { Arterial pH } \\
\text { Lactate }(\mathrm{mmol} / \mathrm{L}) \\
\text { Potassium }(\mathrm{mmol} / \mathrm{L}) \\
\text { I Troponin }(\mathrm{ng} / \mathrm{mL}) \\
\text { Creatinine }(\mu \mathrm{mol} / \mathrm{L}) \\
\text { Glucose }(\mathrm{mmol} / \mathrm{L})\end{array}$ & $\begin{aligned} 7.30 & \pm 0.1 \\
2.7 & \pm 2 \\
4.0 & \pm 1 \\
8.2 & \pm 25 \\
103 & \pm 39 \\
12 & \pm 6\end{aligned}$ & $\begin{array}{c}7.27 \pm 0.1 \\
4.7 \pm 4 \\
3.9 \pm 1 \\
6.1 \pm 19 \\
121 \pm 41 \\
15 \pm 6\end{array}$ & $\begin{array}{c}0.09 \\
\mathbf{0 . 0 0 6} \\
0.42 \\
0.92 \\
\mathbf{0 . 0 1 3} \\
0.61\end{array}$ \\
\hline
\end{tabular}


Qualitative data are expressed as counts and percentages.

CPR: Cardio-Pulmonary Resuscitation; ROSC: Return Of Spontaneous Circulation; VF: Ventricular Fibrillation/ VT: Ventricular tachycardia; PCI: Purcutaneous Coronary Intervention.

The neurological outcome on hospital discharge was favorable ("good outcome" group) for 35 (50\%) patients (CPC 1: 26 patients; CPC 2: 9 patients). The "poor-outcome" group included 35 (50\%) patients (CPC 3: 1 patient, CPC 5: 34 patients).

All pre-hospital delays (no- and low-flows) were shorter in the "good outcome" group. Regardless of the outcome, post resuscitation ECG in the global population showed ST-segment changes in $75 \%$ of patients, including a ST-segment elevation in 26 patients (37\%). The predictive positive and negative values of the latter associated with an acute coronary syndrome (ACS) were $96 \%$ and $41 \%$ respectively, whereas sensitivity and specificity were $49 \%$ and $95 \%$ respectively.

Final diagnosis of OHCA etiology was coronary artery disease for 53 patients (75\%), including 37 $(52 \%)$ of ACS, with similar prevalence in both groups $(60 \%$ in the "good outcome" group vs $46 \%$; $\mathrm{p}=0.3$ ). The remaining causes of OHCA were other cardiomyopathies in 12 patients $(17 \%)$ (dilated in 5 , hypertrophic in 1 , valvulopathy in 5 , and channelopathy in 1 patient ). No etiology was found in 5 patients $(7 \%)$.

Multivariate analysis identified 4 independent factors which are significantly associated with neurological prognosis: a witnessed OHCA (100\% in the "good outcome" group vs $77 \%$, OR=0.18 [0.05-0.80]), an attempted PCI (68 vs $27 \%, \mathrm{OR}=0.11[0.02-0.51])$, a ROSC delay $\geq 25 \mathrm{~min}$ (23 vs $66 \%$ $\mathrm{OR}=6.05[1.58-23.23]$ and a creatinine blood level $\geq 104 \mu \mathrm{mol} / \mathrm{L}$ at hospital admission $(31 \mathrm{vs} 68 \%$ $\mathrm{OR}=4.62[1.23-17.39]$ 


\section{DISCUSSION}

In this population, the survival rate was $51 \%$ and a good neurological outcome was found in $50 \%$ of the patients on hospital discharge, in accordance with literature [6]. This confirms the favorable impact of short delays and the presence of a witness in OHCA. Given the crucial importance of the time from collapse to CPR, efforts should be made to promote the culture of resuscitation not only among health professionals, but also among the general population [7].

Otherwise, more than $80 \%$ of resuscitated patients underwent coronary angiography, in agreement with the fact that approximately $80 \%$ of sudden cardiac deaths are attributed to CAD [8]. Overall, it remains difficult to identify which patients will benefit from early angiography and/or PCI after OHCA, as usual assessment criterion (chest pain and ST elevation) may be poor predictors of ACS in OHCA patients. Indeed, ST-segment elevation has poor accuracy in the setting of post resuscitation [9]: reported sensitivity and specificity of ST-elevation to detect the presence of an underlying acute coronary lesion are $50 \%$ and $88 \%$, respectively [10].This led to the recommendations that emergent coronary angiography may be reasonable in all OHCA patients, regardless of the initial post-ROSC ECG [2]. Furthermore, only PCI and MTH showed in the last decade a positive influence on long term prognosis following OHCA [11,12].

Finally, none of our patients cumulating the four independent prognostic factors of good neurologic outcome (witnessed OHCA, ROSC $<25 \mathrm{~min}$, admission creatinine $<104 \mu \mathrm{mol} / 1$ and PCI) had a poor neurological outcome, even though the small number of patients and the selected population of the study preclude the development of prediction models.

There are several obvious limitations in this study: this is a single-center, retrospective and observational study, thus subject to confounders and selection bias.

\section{CONCLUSION}


Half of the patients hospitalized in our ICCU had a good neurological outcome after a resuscitated OHCA and treatment with MTH. Multivariate analysis showed 4 predictive independent factors of a good neurological outcome: a witnessed OHCA, ROSC $<25 \mathrm{~min}$, admission creatinine $<104 \mu \mathrm{mol} / 1$ and a coronary angioplasty. These findings confirm the importance of public awareness for resuscitation care, and the importance of using emergency coronary angiography, in order to improve the neurological outcome. 


\section{$\underline{\text { References }}$}

1. Neumar RW, Nolan JP, Adrie C et al. Post-cardiac arrest syndrome: epidemiology, pathophysiology, treatment, and prognostication. A consensus statement from the International Liaison Committee on Resuscitation (American Heart Association, Australian and New Zealand Council on Resuscitation, European Resuscitation Council, Heart and Stroke Foundation of Canada, InterAmerican Heart Foundation, Resuscitation Council of Asia, and the Resuscitation Council of Southern Africa); the American Heart Association Emergency Cardiovascular Care Committee; the Council on Cardiovascular Surgery and Anesthesia; the Council on Cardiopulmonary, Perioperative, and Critical Care; the Council on Clinical Cardiology; and the Stroke Council. Circulation 2008;118:2452-83.

2. Peberdy MA, Callaway CW, Neumar RW et al. Part 9: post-cardiac arrest care: 2010 American Heart Association Guidelines for Cardiopulmonary Resuscitation and Emergency Cardiovascular Care. Circulation 2010;122:S768-86.

3. Jennett B, Bond M. Assessment of outcome after severe brain damage. Lancet 1975;1:480-4.

4. Abramson NS, Detre K, Bradley K et al. Impact evaluation in resuscitation research: discussion of clinical trials. Crit Care Med 1988;16:1053-8.

5. Ibrahim JG, Chu H, Chen MH. Missing Data in Clinical Studies: Issues and Methods. J Clin Oncol 2012.

6. Yokoyama H, Nagao K, Hase M et al. Impact of therapeutic hypothermia in the treatment of patients with out-of-hospital cardiac arrest from the J-PULSE-HYPO study registry. Circ J 2011;75:1063-70.

7. Moller Nielsen A, Lou Isbye D, Knudsen Lippert F, Rasmussen LS. Engaging a whole community in resuscitation. Resuscitation 2012;83:1067-71.

8. Chugh SS, Jui J, Gunson K et al. Current burden of sudden cardiac death: multiple source surveillance versus retrospective death certificate-based review in a large U.S. community. J Am Coll Cardiol 2004;44:1268-75.

9. Edgren E, Kelsey S, Sutton K, Safar P. The presenting ECG pattern in survivors of cardiac arrest and its relation to the subsequent long-term survival. Brain Resuscitation Clinical Trial I Study Group. Acta Anaesthesiol Scand 1989;33:265-71.

10. Lellouche N, Sacher F, Jorrot $\mathrm{P}$ et al. Sudden cardiac arrest: ECG repolarization after resuscitation. J Cardiovasc Electrophysiol 2011;22:131-6. 
11. Kern K.B. Optimal treatment of patients surviving out-of-hospital cardiac arrest. JACC Cardiovasc Interv 2012;6:597-605

12. Dumas F, White L, Stubbs BA, Cariou A, Rea TD. Long-term prognosis following resuscitation from out of hospital cardiac arrest: role of percutaneous coronary intervention and therapeutic hypothermia. J Am Coll Cardiol 2012;60:21-7. 